\title{
Smart SUDS: recognising the multiple-benefit potential of sustainable surface water management systems
}

Roshni Jose, Rebecca Wade and Chris Jefferies

(C) IWA Publishing 2015. The definitive peer-reviewed and edited version of this article is published in Water Science \& Technology 71(2): pp.245-251.

doi: http://dx.doi.org/10.2166/wst.2014.484 and is available at www.iwapublishing.com 


\author{
Smart SUDS - Recognising the Multiple Benefit Potential of Sustainable \\ Surface Water Management Systems \\ ${ }^{1}$ Roshni Jose*, Rebecca Wade*, Chris Jefferies** \\ * Urban Water Technology Centre, School of Science, Engineering and Technology, University of Abertay Dundee, \\ Scotland, UK. DD1 1HG. \\ ${ }^{1}$ Email: r.jose@abertay.ac.uk \\ ** Consultant, Urban Drainage Specialist, Scotland.
}

\begin{abstract}
How can we make Sustainable Urban Drainage Systems (SUDS) smart? SUDS help us to manage surface water runoff from urban environments but they are capable of delivering much more. This paper looks beyond the water quantity and quality improvement functions of SUDS and investigates the multiple benefits that can be gained by implementing smart SUDS solutions. This work provides a new perspective, using methodologies not normally associated with SUDS research, to determine multiple benefits. The outputs of the work can potentially assist decision-makers, designer and planners in recognising the potential for multiple benefits that can be delivered by SUDS. The ecosystem services (ES) associated with a large redevelopment in Dundee, Scotland, UK are identified and a public perception study together with Public Participatory GIS methods were used to confirm the goods and benefits of the SUDS. The paper presents findings on the public perception of SUDS as they provide cultural benefits such as; recreation, aesthetics and biodiversity. The results show that greenspace is important while choosing a location and willingness to pay for greenspace is high in this area. This paper concludes that SUDS provide multi-functional benefits in relation to the ES thereby justifying the cachet of Smart SUDS.
\end{abstract}

Key Words: SUDS, Multiple Benefits, Ecosystem Services, Surface Water Management, Public Participatory GIS (PPGIS)

\title{
Introduction
}

In 2011 the United Nations reported that the population in urban areas has increased due to urbanisation over the past few decades and half of the world's population now lives in cities. Furthermore, the world urban population is expected to increase from 3.6 billion in 2011 to 6.3 billion by 2050 (UN 2011). The quality of life and amenity in urban areas are at risk due to increased urban densities making it important to look in to the way we manage our urban settings to identify the multiple benefits provided by them (Wade, Jose and Lundy 2012). According to Potz and Bleuze (2012) water management systems in urban areas with greenspace contribute to functions including recreation, food production, nature development, water storage and purification, pleasant and safe routes for slow traffic, urban lungs and urban cooling. The benefits which humans obtain directly or indirectly from an ecosystem are known as Ecosystem Services (ES) (UKNEA 2011). They are generally categorised as: provisioning services; regulating services; cultural services; and supporting services as per the Millennium Ecosystem Assessment (MEA 2005). This paper will focus on cultural services (CS) which are defined by MEA (2005) as the non-material benefits humans receive from the ecosystem e.g. aesthetics, recreation, spiritual and educational values. In addition, CS are often related to human perceptions, attitudes and beliefs and have strong links to social sciences (Milcu et.al, 2013).

Sustainable Urban Drainage Systems (SUDS) are one method by which urban runoff can be managed at the same time providing opportunities for the improvement of greenspace and environmental quality. SUDS aim to manage storm water as close as possible to its 
source, reducing runoff volumes and rates firstly by infiltrating and where this is not possible, by collecting, temporarily storing and subsequently discharging storm water at a controlled rate to the soil, receiving water body or sewer system (Woods-Ballard 2007). The social aspects of SUDS include local amenity, safety, picnic areas etc. (Heal, McLean and D'Arcy 2004). Amenity is closely related to aesthetics, nature and biodiversity preservation, recreation, public perception and visual appearance of landscapes (Singh 2012). SUDS tend to be needed in urban areas where green and blue corridors that link habitats are needed most. This provides the ideal opportunity to design systems that consider the existing ecological context of the site and aim to maximise biodiversity benefit. People use local parks and open spaces for recreation as they believe that they improve health as well as mental and physical well-being (UKNEA 2011). These areas are also considered to be rich in biodiversity and urban wildlife (DEFRA 2006a).

This research brings ecosystem services and SUDS together in a novel way. SUDS have been implemented for more than 15 years in Scotland, philosophically justified on the basis of the SUDS triangle of quantity, quality and amenity. However, while quantity and quality have been well researched and enumerated using physical science approaches, amenity and other benefits have been less well researched. An ecosystem services approach, utilising social science methods addresses this deficiency. The multiple benefits inherent in SUDS can be evaluated using the approach of ES which is both systematic, and hence can be replicated, and it is applicable in much broader areas than only to SUDS.

\section{Case Study Area}

Ardler Village in Dundee, Scotland, UK is a well-established SUDS site and is one of the first Scottish developments with SUDS designed-in at an early stage. Ardler Village is a suburban area to the north Dundee city which has undergone a series of changes over the years. In the 1980's the area suffered socio-economic issues and Dundee City Council decided to completely redevelop the area (Archibald 2008).

The re-design of the area with installation of SUDS took place in the late 1990's and the main SUDS systems include the West pond, East Pond, Swales and a Detention Basin (Figure 1a). The Ardler West Pond is an on-line pond on the Gelly burn channel which is culverted through a large part of the development. The surface water from housing areas to the north of the pond enters the West pond via swales and then flows out from the rectangular weir structure and towards the East pond through swales. The detention basin act as a flow control mechanism at heavy rainfall. The East pond also controls the water and help to reduce flooding downstream from Ardler.

\section{Methods}

Three methodologies were used to identify the multiple benefits provided by different SUDS features in Ardler. They are

i) Identify the ES related to SUDS

ii) Undertake a Public Perception Study and

iii) Carry out Public Participatory GIS (PPGIS)

Data were collected from greenspace surveys which assessed greenspace use and public perception of ecosystem benefits provided by SUDS in this area. A greenspace map for Ardler (Figure 1a) was attached to the survey. In addition, an interactive mapping method called PPGIS was used, it was designed to provide information about greenspace use in the area and enabled participants to rate their preference for features within their local environment. 


\section{Identify the ES related to SUDS}

A field visit was carried out for visual inspection of ecosystem services at different SUDS amenities in Ardler. The cultural ecosystem services associated with the SUDS systems were identified at this location. Notes and photos were taken at the field site as evidence to the field visit. SUDS at Ardler are vegetated SUDS and they contain flora and fauna which is a sign of rich habitat and biodiversity.

The CS at Ardler and the goods and benefits associated with these services were determined using the approach of Lundy and Wade (2011). Outcomes are given in Table 1 which also shows different measurements which can be used to quantify these services.

Table 1: CS at Ardler and their measurement

\begin{tabular}{|c|c|c|c|c|}
\hline $\begin{array}{ll}\begin{array}{l}\text { Ecosystem } \\
\text { Category }\end{array} & \text { Service } \\
\end{array}$ & $\begin{array}{l}\text { Type of Ecosystem } \\
\text { Services }\end{array}$ & $\begin{array}{ll}\text { ES Goods and } \\
\text { Benefits }\end{array}$ & $\begin{array}{ll}\text { Units } & \text { of } \\
\text { Measurement }\end{array}$ & Reference \\
\hline \multirow[t]{5}{*}{ Cultural Services } & Aesthetics values & $\begin{array}{l}\text { Increase in house } \\
\text { prices }\end{array}$ & $\begin{array}{l}\%-\text { house price } \\
\text { increase }\end{array}$ & $\begin{array}{l}\text { MEA, 2005; Lundy } \\
\text { and Wade, } 2011\end{array}$ \\
\hline & Educational values & $\begin{array}{l}\text { Environmental } \\
\text { awareness }\end{array}$ & $\begin{array}{l}\mathrm{Kg}-\text { Reduced level of } \\
\text { pollution and littering }\end{array}$ & $\begin{array}{l}\text { UKNEA, 2011; MEA, } \\
\text { 2005; Lundy and } \\
\text { Wade, 2011 }\end{array}$ \\
\hline & Sense of place & Mental wellbeing & $\begin{array}{l}\text { In Numbers - Health } \\
\text { statistics }\end{array}$ & MEA, 2005 \\
\hline & $\begin{array}{l}\text { Habitat } \\
\text { Biodiversity }\end{array}$ & $\begin{array}{l}\text { Quality of Greenspace } \\
\text { and environmental } \\
\text { awareness }\end{array}$ & $\begin{array}{l}\text { Presence of flora and } \\
\text { fauna }\end{array}$ & $\begin{array}{l}\text { UKNEA, 2011; MEA, } \\
\text { 2005; Briers, } 2013\end{array}$ \\
\hline & Recreation & $\begin{array}{l}\text { Increases physical } \\
\text { well being }\end{array}$ & $\begin{array}{lll}\% & - & \text { mortality } \\
\text { rates/health statistics }\end{array}$ & $\begin{array}{l}\text { UKNEA, 2011; MEA, } \\
\text { 2005; Lundy and } \\
\text { Wade, 2011 }\end{array}$ \\
\hline
\end{tabular}

(This table is based on Lundy and Wade 2011)

\section{Public Perception Study}

A greenspace survey was carried out to identify the public perception of greenspace there by identifying the multiple benefits provided by ecosystem services in this area. A questionnaire was posted them through the doors of selected houses in the village. A map (Figure 1a) of the area was attached to the questionnaire to locate the SUDS amenities. The greenspace around the SUDS was also highlighted in the map to convey a basic understanding of the area drainage and SUDS arrangements in the area. The main greenspace areas were named and pictures of the main SUDS features were shown so that people could correlate their knowledge of the area with the SUDS.

The houses for the questionnaire were selected on the basis of the visibility of the SUDS features from each house and their distance to the greenspace. 500 questionnaires were distributed among residents in Ardler. Each was colour-coded based on the street in order to locate the street if the resident had not provided their address which in turn will help to carry out some analysis based on geographical location. Completed questionnaires were collected from the Ardler Village Trust (AVT) and Sanctuary Housing offices for further analysis. 


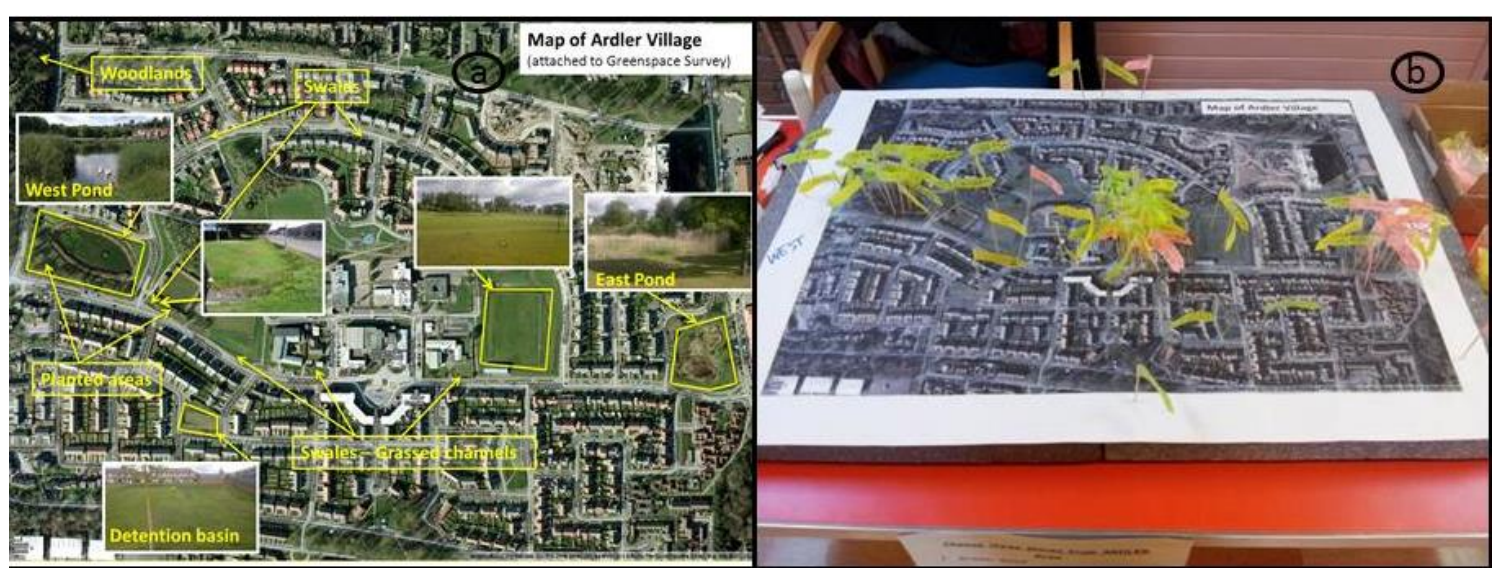

Figure 1: a) Greenspace Map at Ardler b) Map of Ardler with the different coloured flags placed by participants to identify greenspace preference (sources: Google Map)

\section{Public Participatory GIS}

Public Participatory Geographical information System (PPGIS) is a GIS method developed to encourage public participation in the study. The concept has emerged from participatory approaches to planning, spatial information and communication management in the context of the developing world (Cinderby. et. al. 2011). The technique also helps to engage a wider cross-section of people in the local community than a conventional consultation exercises (Cinderby 2009).

The purpose of the PPGIS work was to acquire information about the use of greenspace in the area. An aerial photo of the area (Figure 1b) allowed participants to select their preferred greenspace. Three flags (green, yellow and red) were given to participants to choose their favourite areas in Ardler Village. A traffic lights system was used as it was quick and straightforward for participants. Green flags were used to identify the participant's most favourite place, yellow their mid choice and red for their least favourite place. The research was targeted to the residents in Ardler Village and the Ardler Complex was selected for the participatory activities since most residents take part in community activities and was happy to give their opinion about the area. The Complex workers were included as most were aware of the functions of SUDS systems.

\section{Results and Discussions}

\section{Identification of Cultural Ecosystem Services from SUDS}

Visual assessments of ES provision at Ardler suggested that there was potential for SUDS to deliver supporting, regulating and cultural services, however there was less potential for provisioning services. Table 1 gives an indication of the CS at Ardler and how these services can be measured. The SUDS features in Ardler were developed considering amenity and recreational factor. The mowed grass serves as a recreational area. People prefer to go for a walk near SUDS features as it provides a sense of wellbeing as well as physical wellbeing whereas the sign boards act as a source for educational benefits. The detention basin can be used as a football ground or play area for kids when it is dry. The SUDS systems were also aesthetically pleasing as there was less pollution and litter.

SUDS vegetation consists of grasses, reeds, dandelions and many other plant species. There are many birds and insect species like coots, ducks, swan, bugs, flies, worms, frogs, 
nematodes etc. The West pond is rich in flora and fauna though East pond does not have swans and ducks. The cultural ecosystem services provided by blue-green spaces include spiritual value, educational value, aesthetics and recreation, the results here agreeing with Lundy and Wade (2011)'s results about vegetated filters providing educational value and aesthetics.

\section{Public Perception Study}

In the public perception study carried out in Ardler, 32 questionnaires were returned including 7 face to face surveys. The total return rate was 8\% (Response Rate 1(RR1)) according to the AAPOR (The American Association for Public Opinion Research 2009) definition of survey return rates. Scottish Index of Multiple Deprivation (SIMD) for the area was checked to understand the social background of responders. Ardler falls within $15 \%$ of the most deprived areas in Scotland (Scottish Government 2012). The basic trends and relationships were determined from the survey to know how people perceive greenspace in their local area.

The survey results show that $50 \%$ of respondents use greenspace every day. This result can be compared with the Ardler demonstrating links study (AVT 2007) which reported that $60 \%$ of respondents use greenspace daily in Ardler. Results from this research shows that $60 \%$ of people could view greenspace from their house. In addition, $50 \%$ were willing to pay extra for a house near greenspace and $66 \%$ of people believe that the quality of greenspace is improved after SUDS were established in the area. The survey results shows that, grassed area (47\%) is the most preferred greenspace, then woodlands (44\%), Ponds $(34 \%)$ and finally planted areas $(25 \%)$. The CS which provided high level of multiple benefits according to respondents were recreation, biodiversity, health and aesthetics.

SUDS terminology was familiar to $33 \%$ of respondents though $60 \%$ were not aware of SUDS term. Among respondents who were aware of SUDS terminology $76 \%$ of them knew SUDS functions. This can be compared with previous studies; Apostolaki et.al. (2006) mentioned only 6\% of SUDS awareness; and Bastien et.al (2011) reported 26\% of SUDS awareness. Thus, $25 \%$ of total respondents were aware of the function of SUDS and it shows that people who live close to them have SUDS knowledge.

SUDS in Ardler provide higher recreational, health, sense of wellbeing and aesthetics value associated with greenspace in this area (Figure 2a). They also provide high educational, biodiversity and security values but, social value and religious wellbeing were reported as low in this area. These are the perceived benefits provided by SUDS from the list of benefits given by the researcher to the respondents. The aesthetics value is considered to be high for green urban areas by people.

\section{Public Participatory GIS}

The results from the PPGIS (Figure 2b) interactive mapping method show people's perception of the West pond, East Pond and Complex at Ardler. Ardler West pond is considered as good by $83 \%$ of participants because of amenity and biodiversity values. They have a high acceptance in the area due to a well maintained grassed area which is used for walking, pet walking and other recreational uses. The overgrown reeds which disrupt the view of water body and the failure to clean up dog faeces by some people gave a $7 \%$ poor score. Ardler East pond functions as a storm water drainage pond and dense vegetation provides biodiversity and habitat leading to a $20 \%$ good score whereas the accessibility issues and unkempt look gave a poor score $(60 \%)$ as it is perceived to be dangerous because of 
overgrown reeds, bushes and large fences. Other areas which were picked up include woodlands, football pitches, parks, golf courses, basketball court, clinic, footpath signal etc. Ardler Complex is considered to be attractive and useful by $91 \%$ of respondents. This is because it is a community centre and people in and around Ardler visit there even if they do not notice greenspace in the area. Results for the Ardler Complex have been included in this study as a control to people's preference for greenspace over the community and leisure centre as previous studies shows that built environments can also be restorative as natural environment (Ivarsson and Hagerhall 2008).

The recreational, biodiversity and aesthetics benefits at West pond have given it a better score of $30 \%$ by Ardler residents (Figure 2c) whereas untidy and unkempt look has given the East Pond a poor score $(24 \%)$. People also believe that well-maintained reeds and access to the water body can reduce the negative perception of East Pond. The results from this study match the results from a previous study (AVT 2007) at Ardler regarding the greenspace use. According to AVT (2007) 60\% of the people reported the West pond as most valued greenspace compared to other greenspace in Ardler though litter and less amenity factors in the East Pond area made $31 \%$ of respondents to dislike this location.

SUDS ponds in Ardler are engineered structures which provide buffers to peak flows of water during heavy rain fall. The West pond retains water up to a depth of $70 \mathrm{~cm}$ whereas the East pond has an area of shallow water which can be seen when the reeds are not overgrown. The East pond provides good habitat for plant even though it is not reported by residents to be aesthetically pleasing pond. The results from the public perception of both ponds in this research are similar to the results of public perception survey conducted by Talent (2011) in Ardler. According to Bastien, Arthur and McLoughlin (2011) and Apostolaki, Jefferies and Wild (2006) the public are vaguely aware about the functions of SUDS systems. This could be part of the reason why East pond is less preferred by local residents. 


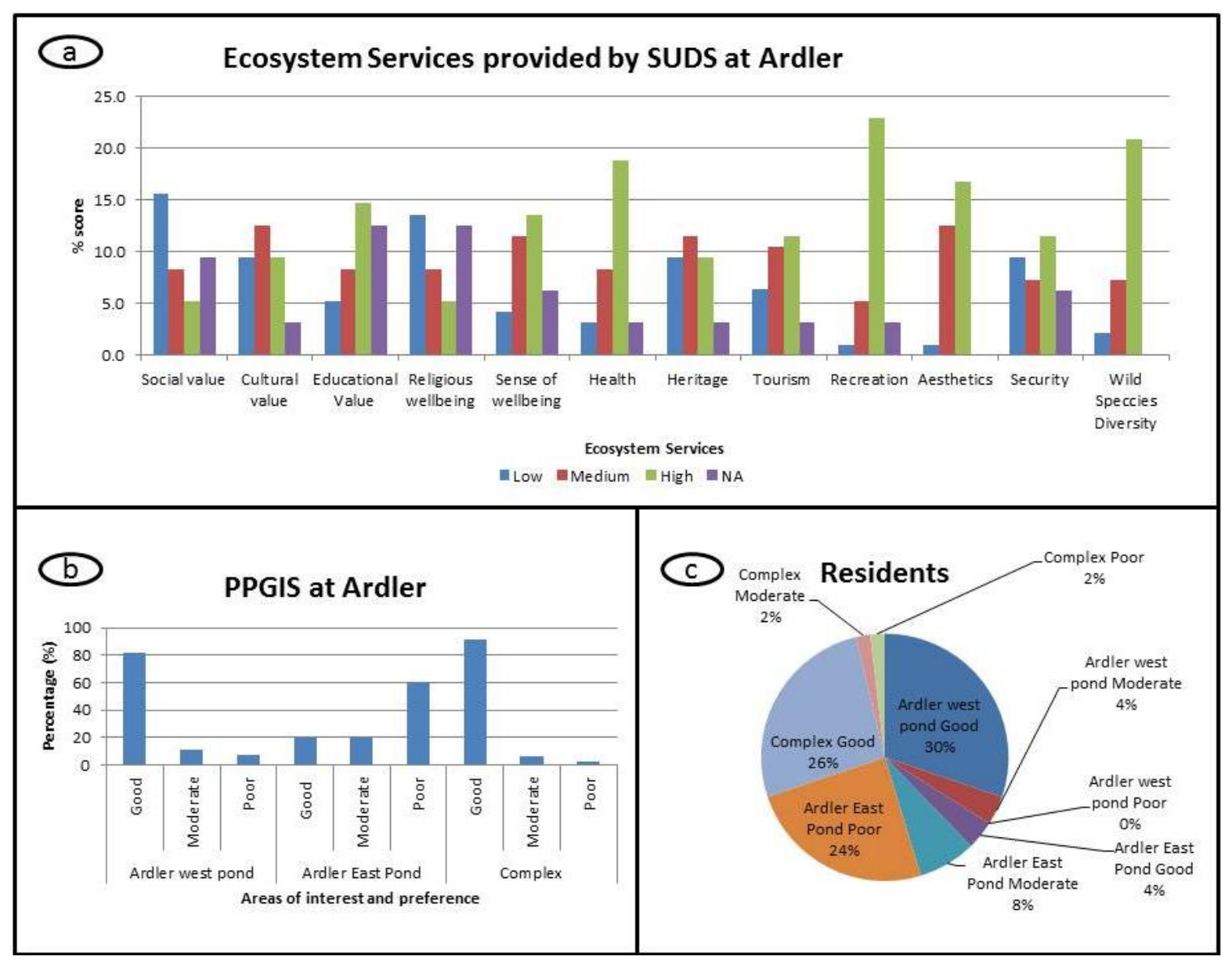

Figure 2: a) Ecosystem provided by SUDS; b) PPGIS results at Ardler; c) Residents opinion aboout Ardler

\section{Measures for improvements}

While it is not the purpose of this paper to propose measures for improvement to SUDS, some solutions and ideas are proposed which could improve the public perception of SUDS (as defined from the results of this study) and can be identified using the ES approach.

- Public perception scores from this study indicate a preference for SUDS which have perceived high values for biodiversity and amenity. In addition SUDS features which appear to be well maintained and which are visually accessible as preferred.

- Addition or enhancement of these characteristics could increase the ES value provided by SUDS.

- Design characteristics of SUDS which could enhance public perception include: amenity (for instance; recreational, educational and aesthetic amenity), biodiversity, evidence of maintenance (including removal of litter and dog faeces - or provision of more bins, provision of signage), and accessibility.

In order to understand more fully the links between design characteristics and public perception, more consistent data collection over longer time periods is required. This is the case not only for SUDS but also regarding the use of environmental setting e.g. leisure, recreation, tourism goods etc. (UKNEA 2011).

The key ES drivers for SUDS are regulating services (water quality and quantity management), cultural services can be improved by introducing well-maintained blue-green spaces which encourages more biodiversity and educational value thereby adding value to the multiple benefits provided. SUDS contribute to sustainable development of urban areas by providing safe, resilient and sustainable water management systems. This can be measured by 
monitoring the well-being and health benefits provided by urban areas (UN 2012), including SUDS.

\section{Conclusions}

SUDS can provide many benefits to people who live near them. Designing a SUDS system appropriately can maximise the functional benefits of water quality and water quantity in any urban area by reducing the pollutants entering the receiving water courses and reducing flooding within and downstream of the catchment. The links between ES and SUDS have been identified in this paper using social science methodologies such as public survey questionnaire and PPGIS. The trends and relationship between goods and benefits generated by SUDS in a case study location, as reported by respondents, were noted.

These results indicate that vegetated SUDS contribute more to CS than other ES. The social science methods used have helped to identify the less-tangible benefits provided by SUDS such as the aesthetics of open spaces, sense of well-being, as well as educational and recreational values. SUDS contribution to amenity values and biodiversity is highly valued by respondents in this study. Previous studies also show that wildlife is one of the main benefits of vegetated SUDS (Helfield and Diamond, 1997).

Greenspaces are highly accepted in the community and the residents are willing to pay more for properties near greenspace. This finding is supported by previous studies at Ardler (Talent 2011) and in other areas. Bastien et.al. (2011) state that willingness to pay for SUDS is high because wildlife is considered as the most important feature provided by SUDS. Results presented in this paper show that for Ardler, the West pond is more acceptable to locals than the East pond. The former is perceived to be safe, non-polluted and contributes to aesthetics and wildlife compared to the latter which has dense vegetation and unkempt surroundings. It is clear from this example that some measures can be used to improve the perception of SUDS, this study presents characteristics which add value to the multiple benefits provided by SUDS, as defined by local residents and respondents in an area with well-established and mature SUDS.

Thus, SUDS systems not only control water quality and quantity but also provide cultural and social benefits. They can become 'Smart SUDS' by utilising appropriate design and maintenance which improve their function, amenity, social acceptability and desirability.

\section{Acknowledgements}

This research was funded by SORSAS (Scottish Overseas Research Student Award Scheme). The field work costs and other expenses were covered by the Urban Water Technology Centre at Abertay University. I would also like to acknowledge my colleagues for assistance, and Ardler Village Trust, Sanctuary Housing and Ardler Environmental Group for their support.

\section{References}

Apostolaki, S., Jefferies, C. and Wild, T. 2006. The Social Impact of Stormwater Management Techniques. Water Practice Technology, 1 (1).

Archibald, M. 2008. Ardler a thriving community. Ardler Village Trust. Dundee.

AVT (Ardler Village Trust). 2007. Demonstrating the links. A study in to the link between the quality of Ardler Greenspace and its use. Dundee. 
Bastien, N.R.P., Arthur, S. and McLoughlin, M.J. 2011. Public Perception of SuDS pondsValuing Amenity. $12^{\text {th }}$ International Conference on Urban Drainage, Porto Algre/Brazil. 1116 Sept 2011.

Briers, R.A. 2013. Invertebrate communities and environmental conditions in a series of urban drainage ponds in Eastern Scotland: Implications for Biodiversity and conservation value of SUDS. Clean - Soil, Air, Water. 42(2). pp:193-200. DOI: 10.1002/clen.201300162

Cinderby, S. 2009. How to reach the 'hard-to-reach': the development of Partocipatory GeoFigureic Information Systems (P-GIS) for inclusive urban design UK. Area. 42(2). pp: 239-251.

Cinderby, Steve. et al. 2011. Participatory geographic information systems for agricultural water management scenario development: A Tanzanian case study. Physics and Chemistry of the Earth. Elsevier. 36. pp: 1093-1102.

Defra. (Department of Environment, fisheries and Rural affairs) 2006a. Working with the grain of nature- taking it forward. Volume II. Measuring progress on the England Biodiversity Strategy: 2006 Assessment. Defra. London.

Heal, K., McLean, N. and D'Arcy, B. 2004. SUDS and Sustainability. $26^{\text {th }}$ Meeting of Standing Conference on stormwater source control, Dunfermline.

Helfield, J.M. and Diamond, M.L. 1997. Use of constructed wetlands for Urban Stream Restoration: A Critical Analysis. Environmental Management. 21(3): pp. 329-341

Ivarsson, C.T. and Hagerhall, C.M. 2008. The perceived restorativeness of gardens Assessing the restorativeness of a mixed built and natural scene type. Urban Forestry \& Urban Greening. 7(2). pp: 107-118.

Lundy, L and Wade, R. 2011. Integrating sciences to sustain urban ecosystem services. Progress in Physical Geography. 35 (5): pp. 653-669

MEA. (2005). Ecosystems and Human Well-being A Framework for Assessment. Island Press. Washington D.C.

Milcu, A. Ioana, J. Hanspach, D. Abson, and J. Fischer (2013). Cultural ecosystem services: a literature review and prospects for future research . Ecology and Society 18(3):44.

Potz, H. and Bleuze, P. 2012. Urban green-blue grids for sustainable and dynamic cities. SKINT. Coop for life. Netherlands.

Scottish Government. 2012. SIMD 2012 Local Authority Summary - Dundee City. [Online] Available at:

http://www.scotland.gov.uk/Topics/Statistics/SIMD/Publications/LASummariesSIMD12/LA $\underline{\text { SummaryDundeeCity12 }}$

Singh, R. 2012. Integrating the planning of greenspaces and sustainable urban drainage systems. PhD Thesis. University of Abertay Dundee. 
Talent, S.N.L. 2011. Evaluation of the Ecosystem Services provided by Sustainable Urban Drainage Systems (SUDS) in Ardler, Dundee. MSc Thesis. Abertay University . Dundee

The American Association for Public Opinion Research. (ed) (2009) Standard Definitions. Final Dispositions of Case Codes and Outcome Rates for Surveys (6th edn). AAPOR. Deerfield, IL.

UKNEA. 2011. The UK National Ecosystem Assessment: Technical Report. UNEP-WCMC. Cambridge.

Woods-Ballard, B . et al. (2007) The SUDS Manual. London. CIRIA, Sharing knowledge, building best practice.

United Nations (UN). 2011. World Urbanization Prospects. The 2011 Revision. New York. Available at: http://esa.un.org/unpd/wup/pdf/WUP2011_Highlights.pdf (accessed 22 Oct 2014)

United Nations. 2012. Sustainable development Knowledge platform. Rio20+ Outcome document - open working group on sustainable development goals. [Online]. Available at: http://sustainabledevelopment.un.org/focussdgs.html

Wade, R., Jose, R. and Lundy, L. (2012) Ecosystem Services delivered by SUDS. Agriculture and the environment IX, valuing ecosystems: policy, economic and management interactions. Proceedings of the SAC and SEPA biennial conference. Edinburgh. 3-4 ${ }^{\text {th }}$ April.

Woods-Ballard, B. et al. (2007) The SUDS Manual. London. CIRIA, Sharing knowledge, building best practice. 